Article DOI: $\underline{\text { http://dx.doi.org/10.3201/eid2010.140288 }}$

\title{
Ongoing Epidemic of Cutaneous Leishmaniasis among Syrian Refugees, Lebanon
}

Technical Appendix
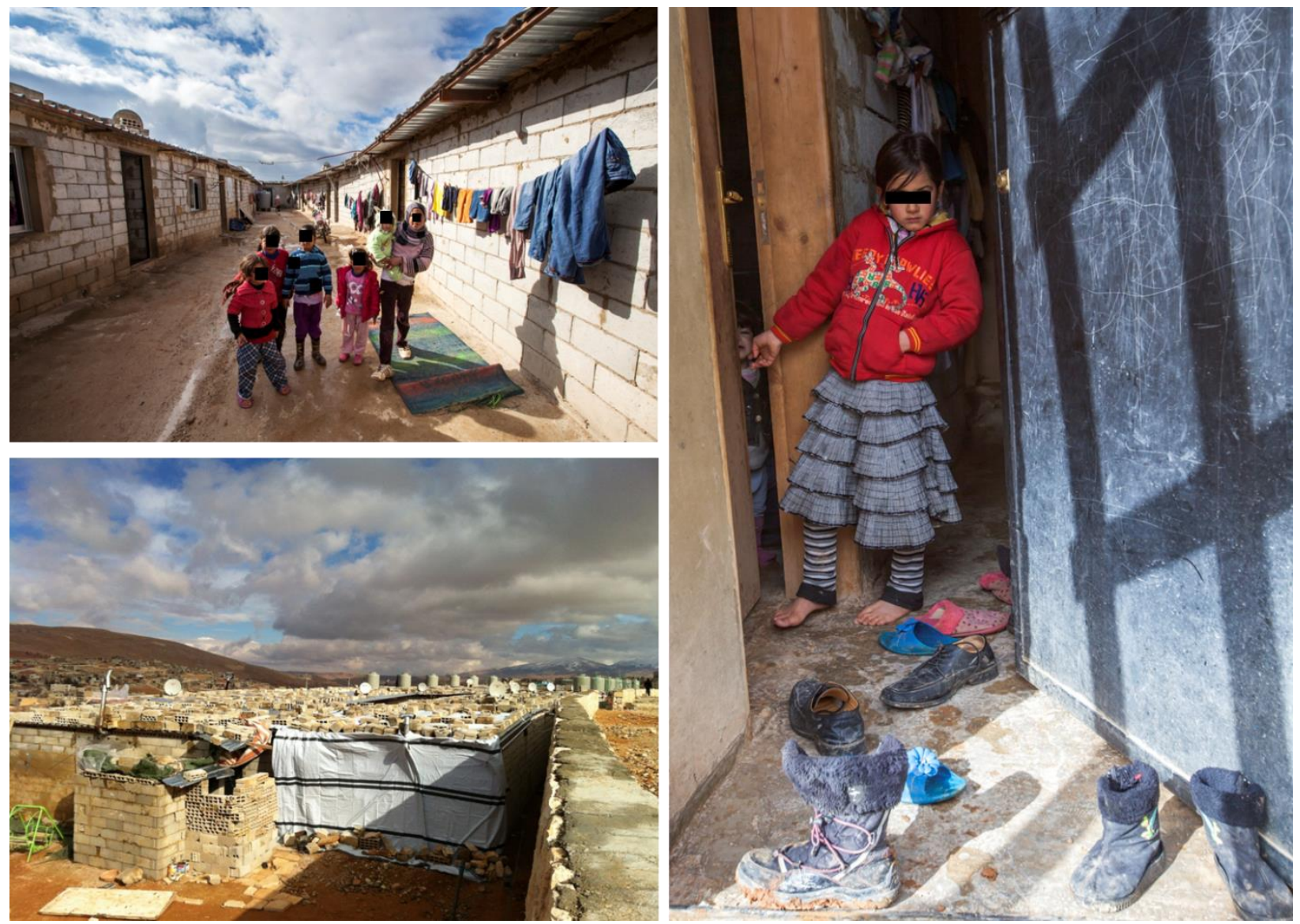

$30 \frac{3}{210}$

Technical Appendix Figure. Syrian refugees in temporary, unsanitary, resource-poor settlements, which are breeding grounds for disease and disease vectors, Beirut, Lebanon, 2012. 